\title{
INDICADORES ECONÔMICOS
}

\begin{tabular}{|c|c|c|c|c|c|c|c|}
\hline \multicolumn{8}{|c|}{ Índices de Preços } \\
\hline \multirow{2}{*}{\multicolumn{2}{|c|}{ Período }} & \multicolumn{3}{|c|}{ IPC/FIPE } & \multicolumn{3}{|c|}{ IPCA } \\
\hline & & Mensal & No ano & Em 12 meses & Mensal & No ano & Em 12 meses \\
\hline \multirow{12}{*}{2006} & Jan. & 0,50 & 0,50 & 4,46 & 0,59 & 0,59 & 5,70 \\
\hline & Fev. & $-0,03$ & 0,47 & 4,06 & 0,41 & 1,00 & 5,51 \\
\hline & Mar. & 0,14 & 0,61 & 3,40 & 0,43 & 1,44 & 5,32 \\
\hline & Abr. & 0,01 & 0,62 & 2,57 & 0,21 & 1,65 & 4,63 \\
\hline & Maio & $-0,22$ & 0,40 & 1,97 & 0,10 & 1,75 & 4,23 \\
\hline & Jun. & $-0,31$ & 0,10 & 1,86 & $-0,21$ & 1,54 & 4,03 \\
\hline & Jul. & 0,21 & 0,31 & 1,76 & 0,19 & 1,73 & 3,97 \\
\hline & Ago. & 0,12 & 0,43 & 2,09 & 0,05 & 1,78 & 3,84 \\
\hline & Set. & 0,24 & 0,68 & 1,90 & 0,21 & 2,00 & 3,70 \\
\hline & Out. & 0,38 & 1,06 & 1,65 & 0,33 & 2,33 & 3,26 \\
\hline & Nov. & 0,41 & 1,48 & 1,78 & 0,31 & 2,65 & 3,02 \\
\hline & Dez. & 1,04 & 2,55 & 2,55 & 0,48 & 3,14 & 3,14 \\
\hline \multirow{12}{*}{2007} & Jan. & 0,66 & 0,66 & 2,71 & 0,44 & 0,44 & 2,99 \\
\hline & Fev. & 0,33 & 0,99 & 3,08 & 0,44 & 0,88 & 3,02 \\
\hline & Mar. & 0,11 & 1,10 & 3,05 & 0,37 & 1,26 & 2,96 \\
\hline & Abr. & 0,33 & 1,44 & 3,38 & 0,25 & 1,51 & 3,00 \\
\hline & Maio & 0,36 & 1,80 & 3,98 & 0,28 & 1,79 & 3,18 \\
\hline & Jun. & 0,55 & 2,36 & 4,88 & 0,28 & 2,08 & 3,69 \\
\hline & Jul. & 0,27 & 2,64 & 4,94 & 0,24 & 2,32 & 3,74 \\
\hline & Ago. & 0,07 & 2,71 & 4,89 & 0,47 & 2,80 & 4,18 \\
\hline & Set. & 0,24 & 2,96 & 4,89 & 0,18 & 2,99 & 4,14 \\
\hline & Out. & 0,08 & 3,04 & 4,58 & 0,30 & 3,30 & 4,11 \\
\hline & Nov. & 0,47 & 3,52 & 4,64 & 0,38 & 3,69 & 4,19 \\
\hline & Dez. & 0,82 & 4,37 & 4,41 & 0,74 & 4,46 & 4,46 \\
\hline \multirow{12}{*}{2008} & Jan. & 0,52 & 0,52 & 4,27 & 0,54 & 0,54 & 4,56 \\
\hline & Fev. & 0,19 & 0,71 & 4,12 & 0,49 & 1,03 & 4,61 \\
\hline & Mar. & 0,31 & 1,02 & 4,33 & 0,48 & 1,52 & 4,73 \\
\hline & Abr. & 0,54 & 1,57 & 4,55 & 0,55 & 1,65 & 5,04 \\
\hline & Maio & 1,23 & 2,27 & 5,26 & 0,79 & 2,32 & 5,57 \\
\hline & Jun. & 0,96 & 2,54 & 5,17 & 0,74 & 3,08 & 6,06 \\
\hline & Jul. & 0,45 & 3,01 & 5,36 & 0,53 & 3,62 & 6,36 \\
\hline & Ago. & 0,38 & 3,40 & 5,69 & 0,28 & 3,91 & 6,16 \\
\hline & Set. & 0,38 & 3,79 & 5,84 & 0,26 & 4,18 & 6,25 \\
\hline & Out. & 0,50 & 4,31 & 6,28 & 0,45 & 4,65 & 6,41 \\
\hline & Nov. & 0,39 & 4,72 & 6,19 & 0,36 & 5,03 & 6,39 \\
\hline & Dez. & 0,16 & 4,88 & 5,50 & 0,28 & 5,32 & 5,90 \\
\hline \multirow{9}{*}{2009} & Jan. & 0,46 & 0,46 & 6,27 & 0,48 & 0,48 & 5,84 \\
\hline & Fev. & 0,27 & 0,73 & 5,52 & 0,55 & 1,03 & 5,90 \\
\hline & Mar. & 0,40 & 1,14 & 6,28 & 0,20 & 1,23 & 5,61 \\
\hline & Abr. & 0,31 & 1,46 & 6,04 & 0,48 & 1,72 & 5,53 \\
\hline & Mai. & 0,33 & 1,78 & 5,10 & 0,47 & 2,20 & 5,20 \\
\hline & Jun. & 0,13 & 1,91 & 4,24 & 0,36 & 2,57 & 4,80 \\
\hline & Jul. & 0,33 & 2,25 & 4,11 & 0,24 & 2,81 & 4,50 \\
\hline & Ago. & 0,48 & 2,74 & 4,22 & 0,15 & 2,97 & 4,36 \\
\hline & Set. & 0,16 & & & & & \\
\hline
\end{tabular}


Índices de Preços

\begin{tabular}{|c|c|c|c|c|c|c|c|}
\hline \multirow{2}{*}{\multicolumn{2}{|c|}{ Período }} & \multicolumn{3}{|c|}{ IGP-M } & \multicolumn{3}{|c|}{ IGP-DI } \\
\hline & & Mensal & No ano & Em 12 meses & Mensal & No ano & Em 12 meses \\
\hline \multirow{12}{*}{2006} & Jan. & 0,92 & 0,92 & 1,74 & 0,72 & 0,72 & 1,62 \\
\hline & Fev. & 0,01 & 0,93 & 1,44 & $-0,06$ & 0,66 & 1,16 \\
\hline & Mar. & $-0,23$ & 0,70 & 0,35 & $-0,45$ & 0,21 & $-0,29$ \\
\hline & Abr. & $-0,42$ & 0,28 & $-0,92$ & 0,02 & 0,23 & $-0,77$ \\
\hline & Maio & 0,38 & 0,66 & $-0,32$ & 0,38 & 0,61 & $-0,15$ \\
\hline & Jun. & 0,75 & 1,41 & 0,87 & 0,67 & 1,28 & 0,98 \\
\hline & Jul. & 0,18 & 1,59 & 1,39 & 0,17 & 1,45 & 1,56 \\
\hline & Ago. & 0,37 & 1,97 & 2,44 & 0,41 & 1,87 & 2,78 \\
\hline & Set. & 0,29 & 2,27 & 3,28 & 0,24 & 2,11 & 3,17 \\
\hline & Out. & 0,47 & 2,75 & 3,15 & 0,81 & 2,94 & 3,35 \\
\hline & Nov. & 0,75 & 3,52 & 3,51 & 0,57 & 3,53 & 3,60 \\
\hline & Dez. & 0,32 & 3,85 & 3,85 & 0,26 & 3,80 & 3,79 \\
\hline \multirow{12}{*}{2007} & Jan. & 0,50 & 0,50 & 4,03 & 0,43 & 0,43 & 3,97 \\
\hline & Fev. & 0,27 & 0,77 & 3,18 & 0,23 & 0,66 & 3,29 \\
\hline & Mar. & 0,34 & 1,11 & 4,38 & 0,22 & 0,88 & 4,26 \\
\hline & Abr. & 0,04 & 1,15 & 3,46 & 0,14 & 1,02 & 3,90 \\
\hline & Maio & 0,04 & 1,19 & 4,86 & 0,16 & 1,19 & 4,41 \\
\hline & Jun. & 0,26 & 1,46 & 3,33 & 0,26 & 1,45 & 3,78 \\
\hline & Jul. & 0,28 & 1,74 & 3,89 & 0,37 & 1,82 & 4,10 \\
\hline & Ago. & 0,98 & 2,74 & 4,28 & 1,39 & 3,24 & 5,04 \\
\hline & Set. & 1,29 & 4,06 & 5,82 & 1,17 & 4,45 & 4,88 \\
\hline & Out. & 1,05 & 5,16 & 4,12 & 0,75 & 5,23 & 5,58 \\
\hline & Nov. & 0,69 & 5,88 & 4,12 & 1,05 & 6,34 & 5,13 \\
\hline & Dez. & 1,76 & 7,75 & 5,33 & 1,47 & 7,90 & 6,52 \\
\hline \multirow{12}{*}{2008} & Jan. & 1,09 & 1,09 & 6,63 & 0,99 & 0,99 & 5,90 \\
\hline & Fev. & 0,53 & 1,63 & 5,36 & 0,38 & 1,37 & 6,47 \\
\hline & Mar. & 0,74 & 2,38 & 7,13 & 0,70 & 2,08 & 6,40 \\
\hline & Abr. & 0,69 & 3,08 & 5,73 & 1,12 & 3,23 & 7,42 \\
\hline & Maio & 1,61 & 4,74 & 8,81 & 1,88 & 5,17 & 8,24 \\
\hline & Jun. & 1,98 & 6,82 & 7,78 & 1,89 & 7,16 & 9,28 \\
\hline & Jul. & 1,76 & 8,70 & 8,74 & 1,12 & 8,36 & 9,17 \\
\hline & Ago. & $-0,32$ & 8,35 & 5,10 & $-0,38$ & 7,94 & 8,46 \\
\hline & Set. & 0,11 & 8,47 & 7,88 & 0,36 & 8,33 & 8,06 \\
\hline & Out. & 0,98 & 9,53 & 7,45 & 1,09 & 9,51 & 8,38 \\
\hline & Nov. & 0,38 & 9,95 & 8,01 & 0,07 & 9,59 & 7,33 \\
\hline & Dez. & $-0,13$ & 9,81 & 4,24 & $-0,44$ & 9,11 & 6,78 \\
\hline \multirow{9}{*}{2009} & Jan. & $-0,44$ & $-0,44$ & 5,54 & 0,01 & 0,01 & 5,79 \\
\hline & Fev. & 0,26 & $-0,18$ & 3,38 & $-0,13$ & $-0,12$ & 7,50 \\
\hline & Mar. & $-0,74$ & $-0,92$ & 6,26 & $-0,84$ & $-0,96$ & 5,85 \\
\hline & Abr. & $-0,15$ & $-1,07$ & 5,38 & 0,04 & $-0,92$ & 4,72 \\
\hline & Mai. & $-0,07$ & $-1,38$ & 3,64 & 0,18 & $-0,74$ & 2,97 \\
\hline & Jun. & $-0,10$ & $-1,24$ & 1,52 & $-0,32$ & $-1,05$ & 0,74 \\
\hline & Jul. & $-0,43$ & $-1,66$ & $-0,66$ & $-0,64$ & $-1,69$ & $-1,01$ \\
\hline & Ago. & $-0,36$ & $-2,02$ & $-0,70$ & 0,09 & $-1,60$ & $-0,54$ \\
\hline & Set. & 0,42 & $-1,60$ & $-0,39$ & & & \\
\hline
\end{tabular}




\section{Índices de Confiança}

Índice de Confiança do Consumidor (ICC)

\begin{tabular}{cccccc}
\hline Período & $\mathbf{2 0 0 2}$ & $\mathbf{2 0 0 3}$ & $\mathbf{2 0 0 4}$ & $\mathbf{2 0 0 6}$ & $\mathbf{2 0 0 9}$ \\
\hline $1^{\mathrm{o}}$ Trimestre & 105,52 & 105,09 & 115,79 & 136,14 & 127,16 \\
$2^{\mathrm{o}}$ Trimestre & 92,24 & 117,95 & 117,67 & 135,48 & 128,37 \\
$3^{\text {o }}$ Trimestre & 107,78 & 109,77 & 128,81 & 131,61 & 141,92 \\
$4^{\text {o }}$ Trimestre & 114,70 & 118,92 & 141,07 & 131,46 & \\
\hline
\end{tabular}

Fonte: Fecomércio SP.

Índice de Confiança do Empresário Industrial - Geral (ICEI)

\begin{tabular}{cccccc}
\hline Período & $\mathbf{2 0 0 2}$ & $\mathbf{2 0 0 3}$ & $\mathbf{2 0 0 4}$ & $\mathbf{2 0 0 6}$ & $\mathbf{2 0 0 9}$ \\
\hline $1^{\circ}$ Trimestre & 58,9 & 57,2 & 56,3 & 56,4 & 47,40 \\
$2^{\circ}$ Trimestre & 48,5 & 51,9 & 60,7 & 54,4 & 49,40 \\
$3^{\circ}$ Trimestre & 49,5 & 55,8 & 63,8 & 56,6 & $58,2^{1}$ \\
$4^{\circ}$ Trimestre & 58,9 & 62,4 & 64,9 & 60,1 & \\
\hline
\end{tabular}

Fonte: CNI.

Nota: (1) ICEI referente ao mês de Julho somente. 
Índice de Volume de Vendas Reais no Varejo

\begin{tabular}{|c|c|c|c|}
\hline \multicolumn{2}{|c|}{ Período } & Total $^{1}$ & $\begin{array}{c}\text { Veículos, } \\
\text { Motos, Partes e } \\
\text { Peças } \\
\end{array}$ \\
\hline \multirow{12}{*}{2005} & Jan. & 105,15 & 123,60 \\
\hline & Fev. & 96,84 & 115,29 \\
\hline & Mar. & 111,36 & 119,98 \\
\hline & Abr. & 107,75 & 116,25 \\
\hline & Maio & 112,29 & 114,80 \\
\hline & Jun. & 110,12 & 119,38 \\
\hline & Jul. & 114,61 & 118,06 \\
\hline & Ago. & 113,75 & 118,69 \\
\hline & Set. & 109,29 & 116,64 \\
\hline & Out. & 115,46 & 115,27 \\
\hline & Nov. & 114,98 & 123,54 \\
\hline & Dez. & 162,59 & 133,89 \\
\hline \multirow{12}{*}{2006} & Jan. & 112,02 & 121,51 \\
\hline & Fev. & 102,68 & 118,11 \\
\hline & Mar. & 114,67 & 120,04 \\
\hline & Abr. & 115,79 & 123,26 \\
\hline & Maio & 120,59 & 126,13 \\
\hline & Jun. & 114,49 & 112,39 \\
\hline & Jul. & 117,19 & 131,16 \\
\hline & Ago. & 120,91 & 132,66 \\
\hline & Set. & 120,20 & 131,37 \\
\hline & Out. & 123,48 & 131,62 \\
\hline & Nov. & 125,29 & 138,50 \\
\hline & Dez. & 171,76 & 151,65 \\
\hline \multirow{12}{*}{2007} & Jan. & 121,49 & 138,53 \\
\hline & Fev. & 112,06 & 142,26 \\
\hline & Mar. & 127,93 & 150,41 \\
\hline & Abr. & 124,62 & 151,95 \\
\hline & Maio & 133,33 & 154,33 \\
\hline & Jun. & 127,48 & 151,22 \\
\hline & Jul. & 128,08 & 155,68 \\
\hline & Ago. & 133,30 & 168,09 \\
\hline & Set. & 130,18 & 160,51 \\
\hline & Out. & 135,47 & 166,89 \\
\hline & Nov. & 138,31 & 168,85 \\
\hline & Dez. & 188,06 & 167,79 \\
\hline \multirow{12}{*}{2008} & Jan. & 135,83 & 175,56 \\
\hline & Fev. & 126,43 & 179,71 \\
\hline & Mar. & 142,04 & 178,24 \\
\hline & Abr. & 135,47 & 191,14 \\
\hline & Maio & 148,06 & 179,18 \\
\hline & Jun. & 137,91 & 184,35 \\
\hline & Jul. & 142,50 & 195,35 \\
\hline & Ago. & 146,54 & 180,56 \\
\hline & Set. & 142,24 & 186,41 \\
\hline & Out. & 148,79 & 160,53 \\
\hline & Nov. & 145,34 & 142,82 \\
\hline & Dez. & 195,20 & 153,00 \\
\hline \multirow{7}{*}{2009} & Jan. & 143,94 & 183,61 \\
\hline & Fev. & 131,28 & 184,24 \\
\hline & Mar. & 143,93 & 191,33 \\
\hline & Abr. & 145,02 & 180,83 \\
\hline & Mai. & 152,42 & 193,22 \\
\hline & Jun. & 145,72 & 211,12 \\
\hline & Jul. & 150,95 & 189,07 \\
\hline
\end{tabular}

Fonte: Pesquisa Mensal do Comércio (IBGE), IPEA.

Nota: (1)Exceto o comércio de veículos, motocicletas, partes (2)Índice com ajuste sazonal 


\section{Contas Nacionais}

Contas Nacionais

R\$ (milhões) do segundo trimestre de 2009

\begin{tabular}{lcccccc}
\hline Período & PIB & $\begin{array}{c}\text { Consumo das } \\
\text { famílias }\end{array}$ & $\begin{array}{c}\text { Consumo do } \\
\text { governo }\end{array}$ & FBKF & Export. & Import. \\
\hline 2000 & 2.281 .551 & 1.411 .852 & 477.612 & 391.759 & 6.534 & 242.707 \\
2001 & 2.311 .500 & 1.421 .422 & 490.713 & 393.467 & 7.191 & 246.392 \\
2002 & 2.372 .946 & 1.448 .819 & 514.003 & 372.883 & 7.724 & 217.267 \\
2003 & 2.400 .157 & 1.437 .553 & 519.940 & 355.752 & 8.527 & 213.747 \\
2004 & 2.537 .197 & 1.492 .477 & 541.213 & 388.203 & 9.832 & 242.173 \\
2005 & 2.617 .438 & 1.559 .179 & 553.672 & 402.277 & 10.749 & 262.696 \\
2006 & 2.721 .328 & 1.640 .220 & 567.942 & 441.580 & 11.291 & 311.154 \\
2007 & 2.875 .614 & 1.743 .506 & 594.820 & 501.173 & 12.050 & 375.831 \\
$2008 . I$ & 732.187 & 450.880 & 150.562 & 132.649 & 2.689 & 100.340 \\
$2008 . I I$ & 765.078 & 456.513 & 152.510 & 143.112 & 3.142 & 110.319 \\
$2008 . I I I$ & 779.433 & 469.348 & 155.765 & 157.758 & 3.260 & 123.588 \\
$2008 . I V$ & 744.889 & 460.578 & 169.543 & 136.657 & 2.887 & 111.081 \\
2008 & 3.021 .587 & 1.837 .318 & 628.380 & 570.175 & 11.978 & 445.328 \\
2009.I & 719.226 & 456.865 & 154.619 & 114.041 & 2.280 & 84.244 \\
2009.II & 756.197 & 471.172 & 155.903 & 118.778 & 2.785 & 92.127 \\
\hline
\end{tabular}

Fonte: Sistema de Contas Nacionais (IBGE).

Contas Nacionais

Variação Percentual por Período

\begin{tabular}{lcccccc}
\hline Período & PIB & $\begin{array}{c}\text { Consumo das } \\
\text { famílias }\end{array}$ & $\begin{array}{c}\text { Consumo do } \\
\text { governo }\end{array}$ & FBKF & Export. & Import. \\
\hline 2001 & 1,31 & 0,68 & 2,74 & 0,44 & 10,05 & 1,52 \\
2002 & 2,66 & 1,93 & 4,75 & $-5,23$ & 7,42 & $-11,82$ \\
2003 & 1,15 & $-0,78$ & 1,16 & $-4,59$ & 10,40 & $-1,62$ \\
2004 & 5,71 & 3,82 & 4,09 & 9,12 & 15,29 & 13,30 \\
2005 & 3,16 & 4,47 & 2,30 & 3,63 & 9,33 & 8,47 \\
2006 & 3,97 & 5,20 & 2,58 & 9,77 & 5,04 & 18,45 \\
2007 & 5,67 & 6,30 & 4,73 & 13,50 & 6,72 & 20,79 \\
$2008 . I^{*}$ & 6,12 & 6,26 & 6,48 & 15,36 & $-2,33$ & 18,84 \\
$2008 . I^{*}$ & 6,20 & 5,93 & 4,25 & 16,63 & 4,90 & 25,97 \\
$2008 . I I I^{*}$ & 6,81 & 7,31 & 6,39 & 19,69 & 1,97 & 22,82 \\
$2008 . I^{*}$ & 1,27 & 2,16 & 5,49 & 3,78 & $-7,00$ & 7,63 \\
2008 & 5,08 & 5,38 & 5,64 & 13,77 & $-0,60$ & 18,49 \\
$2009 . I^{*}$ & $-1,77$ & 1,33 & 2,69 & $-14,03$ & $-15,23$ & $-16,04$ \\
2009.II* & $-1,16$ & 3,21 & 2,22 & $-17,00$ & $-11,35$ & $-16,49$ \\
\hline
\end{tabular}

Fonte: Sistema de Contas Nacionais (IBGE).

* Variação percentual sobre o mesmo período do ano anterior. 
Finanças Públicas

\begin{tabular}{lccccc}
\hline \multicolumn{1}{c}{ Descrição } & $\mathbf{2 0 0 5}$ & $\mathbf{2 0 0 6}$ & $\mathbf{2 0 0 7}$ & $\mathbf{2 0 0 8}$ & $\mathbf{2 0 0 9}^{(\mathbf{a})}$ \\
\hline DLSP $^{1}-$ Total & 46,50 & 44,70 & 42,80 & 39,39 & 36,98 \\
DLSP $^{2}-$ Externa & 2,30 & $-2,70$ & $-9,00$ & $-10,56$ & $-13,60$ \\
DLSP $^{3}$ - Interna & 44,10 & 47,40 & 51,90 & 49,89 & 50,55 \\
\hline Necessidade Financ. do Set. Público $^{4}$ & 8,11 & 7,66 & 6,25 & 5,59 & 5,30 \\
Superávit Primário $^{5}$ & 4,83 & 4,32 & 3,98 & $-4,07$ & $-2,00$ \\
Déficit Nominal $^{6}$ & 3,28 & 3,35 & 2,27 & 1,53 & 3,30 \\
\hline
\end{tabular}

Fonte: Banco Central.

Nota: (a) Dados contabilizados até Fevereiro de 2008

(1)- Dívida Líquida do Setor Público (\% PIB) - Total - Setor público consolidado - \% - M.

(2)- Dívida Líquida do Setor Público (\% PIB) - Externa - Setor público consolidado - \% - M.

(3)- Dívida Líquida do Setor Público (\% PIB) - Interna - Setor público consolidado - \% - M.

(4)- NFSP c/ desv. cambial (\% PIB) - Acumulado em 12 meses - Juros nominais - Set. público consolidado - \%.

(5)- NFSP c/ desv. cambial (\% PIB) - Acumulado em 12 meses - Resultado primário - Set. público consolidado - \%.

(6)- NFSP s/ desv. cambial (\% PIB) - Acumulado em 12 meses - Resultado nominal -Set. público consolidado - \%.

Receitas e Despesas

\begin{tabular}{|c|c|c|c|c|c|}
\hline Descrição & 2005 & 2006 & 2007 & 2008 & $2009^{(a)}$ \\
\hline Receita Total & 488.375 & 543.251 & 618.872 & 716.647 & 111.188 \\
\hline Receitas do Tesouro & 378.546 & 418.162 & 477.141 & 551.332 & 85.694 \\
\hline Receita Bruta & 392.438 & 431.423 & 490.924 & 564.720 & 86.230 \\
\hline (-) Restituições & -13.884 & -13.260 & -13.772 & -13.388 & -537 \\
\hline (-) Incentivos Fiscais & -7 & 0 & -10 & -1 & 0 \\
\hline Receitas da Previdência & 108.434 & 123.520 & 140.411 & 163.355 & 25.201 \\
\hline Receitas do BCB & 1.394 & 1.569 & 1.319 & 1.745 & 293 \\
\hline Transferências ${ }^{1}$ & 83.936 & 92.779 & 105.604 & 133.074 & 21.392 \\
\hline Receita Líquida Total $^{2}$ & 404.438 & 450.471 & 513.267 & 537.200 & 89.797 \\
\hline Despesa Total & 351.840 & 400.669 & 455.442 & 498.355 & 86.471 \\
\hline Pessoal e Encargos Sociais & 92.230 & 105.030 & 116.372 & 121.370 & 27.676 \\
\hline Benefícios Previdenciários & 146.010 & 165.585 & 185.293 & 182.907 & 34.126 \\
\hline Custeio e Capital & 111.340 & 127.617 & 151.292 & 164.336 & 24.218 \\
\hline Transf. do Tesouro ao BCB & 552 & 695,4 & 520,8 & $1.042,5$ & 162 \\
\hline Despesas do BCB & 1.706 & 1.740 & 1.963 & 2.431 & 289 \\
\hline
\end{tabular}

Fonte: Tesouro Nacional.

Notas: $\left({ }^{*}\right)$ em milhões de R\$.

(a) Dados contabilizados até Janeiro de 2008.

(1) Transferências concedidas aos Estados e Municípios.

(2) Receita Total menos Transferências. 
Atividade Industrial

\begin{tabular}{rrrrrrr}
\hline \multicolumn{1}{c}{ Período } & Bens de capital & $\begin{array}{c}\text { Bens } \\
\text { intermediários }\end{array}$ & $\begin{array}{c}\text { Bens de consumo } \\
\text { duráveis }\end{array}$ & $\begin{array}{c}\text { Bens de cons. } \\
\text { não-duráveis }\end{array}$ & $\begin{array}{c}\text { Indústria de } \\
\text { transformação }\end{array}$ & $\begin{array}{c}\text { Capacidade } \\
\text { instalada (\%) }\end{array}$ \\
\hline Jan. & 143,77 & 114,65 & 148,76 & 108,03 & 108,06 & 82,40 \\
Fev. & 148,04 & 115,03 & 150,33 & 108,95 & 103,21 & 83,90 \\
Mar. & 149,91 & 116,09 & 153,13 & 109,05 & 120,45 & 83,10 \\
Abr. & 150,33 & 116,97 & 154,41 & 109,93 & 112,68 & 84,50 \\
Maio & 152,90 & 117,70 & 156,57 & 110,45 & 124,82 & 84,40 \\
Jun. & 155,45 & 117,72 & 157,98 & 112,06 & 120,81 & 84,70 \\
Jul. & 157,68 & 117,94 & 160,77 & 111,95 & 124,56 & 85,20 \\
Ago. & 159,24 & 118,25 & 163,26 & 111,94 & 131,97 & 85,70 \\
Set. & 161,02 & 118,20 & 165,26 & 110,68 & 123,58 & 86,10 \\
Out. & 164,86 & 119,29 & 168,01 & 111,33 & 136,66 & 87,00 \\
Nov. & 168,41 & 119,88 & 167,93 & 111,58 & 130,11 & 87,20 \\
Dez. & 171,62 & 121,39 & 167,30 & 111,88 & 115,00 & 86,70 \\
\hline Jan. & 173,37 & 122,25 & 168,32 & 112,32 & 117,54 & 84,30 \\
Fev. & 180,40 & 123,65 & 176,62 & 110,26 & 113,24 & 84,70 \\
Mar. & 183,47 & 122,83 & 179,40 & 112,44 & 122,15 & 85,20 \\
Abr. & 187,21 & 121,59 & 176,51 & 111,02 & 124,36 & 85,10 \\
Maio & 174,72 & 121,93 & 172,83 & 112,02 & 127,49 & 85,60 \\
Jun. & 189,25 & 124,52 & 185,59 & 114,36 & 128,60 & 86,30 \\
Jul. & 190,69 & 125,65 & 174,02 & 113,86 & 135,51 & 86,10 \\
Ago. & 188,98 & 122,13 & 175,88 & 112,84 & 134,04 & 86,60 \\
Set. & 194,87 & 121,78 & 177,84 & 115,11 & 135,50 & 86,30 \\
Out. & 193,36 & 117,61 & 171,10 & 112,72 & 137,66 & 86,30 \\
Nov. & 186,39 & 113,41 & 136,11 & 111,80 & 121,64 & 85,20 \\
Dez. & 143,16 & 99,39 & 92,07 & 107,42 & 98,54 & 80,60 \\
\hline Jan. & 151,39 & 101,30 & 124,96 & 106,36 & 97,08 & 76,70 \\
Fev. & 141,17 & 103,37 & 139,80 & 109,39 & 94,35 & 77,00 \\
Mar. & 134,49 & 104,15 & 142,85 & 110,14 & 110,33 & 77,10 \\
Abr. & 137,67 & 105,31 & 146,46 & 110,63 & 105,73 & 77,60 \\
Maio & 139,02 & 106,96 & 152,78 & 111,52 & 113,48 & 78,70 \\
Jun. & 142,04 & 107,84 & 155,89 & 108,78 & 114,53 & 79,10 \\
Jul. & 144,08 & 109,86 & 163,37 & 110,05 & 122,08 & 79,80 \\
Ago. & 144,71 & 110,66 & 168,43 & 110,74 & & 81,60 \\
Set. & & & & & & 82,80 \\
\hline 009 & & & & \\
\hline
\end{tabular}

Fontes: IBGE, Diretoria de Pesquisas, Coordenação de Indústria e Fundação Getúlio Vargas, Conjuntura Econômica. Nota: Séries com ajustes sazonais (2002=100) Média Móvel Trimestral (Jan.2007-Jul.2009), exceto

Capacidade instalada. 


\section{Consumo de Energia}

\section{Carga de energia SIN - GWh}

\begin{tabular}{ccccc}
\hline Período & $\mathbf{2 0 0 6}$ & $\mathbf{2 0 0 7}$ & $\mathbf{2 0 0 8}$ & $\mathbf{2 0 0 9}$ \\
\hline Jan. & $35.486,04$ & $36.590,42$ & $37.834,86$ & $36.340,46$ \\
Fev. & $32.799,81$ & $33.585,69$ & $35.940,73$ & $34.402,84$ \\
Mar. & $36.713,42$ & $38.691,68$ & $38.662,34$ & $39.112,48$ \\
Abr. & $33.576,28$ & $36.099,68$ & $37.389,91$ & $35.808,26$ \\
Maio & $34.244,54$ & $35.999,66$ & $37.215,00$ & $36.190,00$ \\
Jun. & $33.164,09$ & $34.408,62$ & $36.292,02$ & $34.600,00$ \\
Jul. & $34.363,48$ & $35.671,96$ & $37.599,53$ & $36.532,00$ \\
Ago. & $35.479,98$ & $36.597,02$ & $38.408,28$ & $36.908,00$ \\
Set. & $33.847,68$ & $35.897,48$ & $37.241,73$ & $37.000,00$ \\
Out. & $35.448,84$ & $38.092,99$ & $39.275,76$ & \\
Nov. & $34.728,92$ & $36.402,95$ & $36.603,32$ & \\
Dez. & $36.006,62$ & $37.608,00$ & $35.768,70$ & \\
\hline
\end{tabular}

Fonte: Operador Nacional do Sistema 
Taxa de Desemprego

\begin{tabular}{|c|c|c|c|c|c|c|c|c|c|c|}
\hline \multirow{2}{*}{ Período } & \multicolumn{2}{|c|}{2005} & \multicolumn{2}{|c|}{2006} & \multicolumn{2}{|c|}{2007} & \multicolumn{2}{|c|}{2008} & \multicolumn{2}{|c|}{2009} \\
\hline & Média $^{1}$ & $\mathrm{RMC}^{2}$ & Média ${ }^{1}$ & $\mathrm{RMC}^{2}$ & Média ${ }^{1}$ & $\mathrm{RMC}^{2}$ & Média ${ }^{1}$ & $\mathrm{RMC}^{2}$ & Média & $\mathrm{RMC}^{2}$ \\
\hline Jan. & 10,2 & 7,7 & 9,2 & 7,2 & 9,3 & 5,6 & 8,0 & 4,8 & 8,2 & 5,4 \\
\hline Fev. & 10,6 & 8,7 & 10,1 & 7,9 & 9,9 & 6,6 & 8,7 & 5,9 & 8,5 & 6,3 \\
\hline Mar. & 10,8 & 8,5 & 10,4 & 8,2 & 10,1 & 7,1 & 8,6 & 5,8 & 9,0 & 6,3 \\
\hline Abr. & 10,8 & 8,2 & 10,4 & 8,7 & 10,1 & 6,4 & 8,5 & 6,3 & 8,9 & 6,1 \\
\hline Maio & 10,2 & 8,1 & 10,2 & 7,6 & 10,1 & 7,0 & 7,9 & 6,2 & 8,8 & 5,5 \\
\hline Jun. & 9,4 & 7,9 & 10,4 & 6,8 & 9,7 & 7,0 & 7,8 & 6,2 & 8,1 & 5,2 \\
\hline Jul. & 9,4 & 7,6 & 10,7 & 6,7 & 9,5 & 7,2 & 8,1 & 5,8 & 8,0 & 5,6 \\
\hline Ago. & 9,4 & 7,6 & 10,6 & 6,4 & 9,5 & 6,8 & 7,6 & 5,4 & 8,1 & \\
\hline Set. & 9,6 & 7,0 & 10,0 & 6,4 & 9,0 & 6,3 & 7,6 & 4,5 & & \\
\hline Out. & 9,6 & 6,5 & 9,8 & 5,7 & 8,7 & 6,1 & 7,5 & 4,6 & & \\
\hline Nov. & 9,6 & 5,1 & 9,5 & 5,9 & 8,2 & 5,2 & 7,6 & 4,8 & & \\
\hline Dez. & 8,3 & 5,5 & 8,4 & 5,6 & 7,4 & 3,6 & 6,8 & 4,2 & & \\
\hline
\end{tabular}

Fonte: IBGE/PME; Instituto Paranaense de Desenvolvimento Econômico e Social (Ipardes).

Nota: (1) Média do índice em Recife, Salvador, Belo Horizonte, Rio de Janeiro, São Paulo e Porto Alegre.

(2) RMC - Região Metropolitana de Curitiba. 


\section{Pessoal Ocupado e Rendimentos}

\begin{tabular}{|c|c|c|c|c|}
\hline \multicolumn{2}{|c|}{ Período } & População & $\begin{array}{c}\text { Rendimento } \\
\text { Médio Real (R\$) }\end{array}$ & Massa de Rendimento \\
\hline \multirow{12}{*}{2006} & Jan. & 20.006 & $1.018,86$ & 23.686 \\
\hline & Fev. & 19.922 & $1.017,82$ & 23.307 \\
\hline & Mar. & 19.929 & $1.023,90$ & 23.335 \\
\hline & Abr. & 19.974 & $1.036,37$ & 23.883 \\
\hline & Maio. & 19.974 & $1.043,61$ & 23.998 \\
\hline & Jun. & 20.144 & $1.032,90$ & 24.172 \\
\hline & Jul. & 20.229 & $1.028,50$ & 24.494 \\
\hline & Ago. & 20.455 & $1.036,20$ & 24.426 \\
\hline & Set. & 20.699 & $1.030,20$ & 24.878 \\
\hline & Out. & 20.661 & $1.046,50$ & 25.069 \\
\hline & Nov. & 20.731 & $1.056,60$ & 27.248 \\
\hline & Dez. & 20.759 & $1.081,48$ & 30.393 \\
\hline \multirow{12}{*}{2007} & Jan. & 20.518 & $1.106,52$ & 25.054 \\
\hline & Fev. & 20.427 & $1.127,78$ & 25.001 \\
\hline & Mar. & 20.569 & $1.127,40$ & 24.899 \\
\hline & Abr. & 20.501 & $1.130,33$ & 25.128 \\
\hline & Maio. & 20.522 & $1.133,66$ & 25.296 \\
\hline & Jun. & 20.790 & $1.128,12$ & 25.062 \\
\hline & Jul. & 20.832 & $1.114,63$ & 25.304 \\
\hline & Ago. & 21.049 & $1.109,40$ & 25.632 \\
\hline & Set. & 21.250 & $1.117,64$ & 25.712 \\
\hline & Out. & 21.301 & $1.123,60$ & 26.252 \\
\hline & Nov. & 21.449 & $1.153,67$ & 28.262 \\
\hline & Dez. & 21.381 & $1.172,00$ & 33.421 \\
\hline \multirow{12}{*}{2008} & Jan. & 21.261 & $1.172,00$ & 26.415 \\
\hline & Fev. & 21.160 & $1.195,49$ & 26.495 \\
\hline & Mar. & 21.282 & $1.188,90$ & 26.889 \\
\hline & Abr. & 21.387 & $1.219,80$ & 27.022 \\
\hline & Maio & 21.476 & $1.208,20$ & 27.179 \\
\hline & Jun. & 21.723 & $1.216,50$ & 27.002 \\
\hline & Jul. & 21.668 & $1.224,40$ & 27.872 \\
\hline & Ago. & 21.820 & $1.253,70$ & 28.322 \\
\hline & Set. & 21.979 & $1.274,26$ & 28.218 \\
\hline & Out. & 22.155 & $1.258,20$ & 28.307 \\
\hline & Nov. & 22.060 & $1.278,26$ & 30.461 \\
\hline & Dez. & 22.115 & $1.284,90$ & 35.809 \\
\hline \multirow{8}{*}{2009} & Jan. & 21.200 & $1.318,70$ & 28.091 \\
\hline & Fev. & 20.900 & $1.321,30$ & 27.921 \\
\hline & Mar. & 21.000 & $1.321,40$ & 27.931 \\
\hline & Abr. & 20.913 & $1.318,40$ & 27.796 \\
\hline & Maio & 21.000 & $1.305,46$ & 27.931 \\
\hline & Jun. & 21.148 & $1.310,24$ & 28.175 \\
\hline & Jul. & 21.332 & $1.318,94$ & 28.530 \\
\hline & Ago. & 21.444 & $1.336,80^{2}$ & $28.951^{3}$ \\
\hline
\end{tabular}

Fonte: IBGE.

Nota: (1) Massa de Rendimento Real Efetivo de Todos os Trabalhos a preços de Agosto de 2009 -(em milhões)

(2) Rendimento Médio Real Habitual a preços de Agosto

(3)Massa de Rendimento Real Habitual de Todos os Trabalhos a preços de Agosto de 2009 (em milhões) 
Taxa de Juros e Reservas Internacionais

Taxa de Juros

\begin{tabular}{|c|c|c|c|}
\hline$\overline{\text { Per }}$ & odo & Meta Selic ${ }^{1}$ & Selic efetiva \\
\hline \multirow{12}{*}{2005} & Jan. & 18,25 & 18,25 \\
\hline & Fev. & 18,75 & 18,75 \\
\hline & Mar. & 19,25 & 19,24 \\
\hline & Abr. & 19,50 & 19,51 \\
\hline & Maio & 19,75 & 19,75 \\
\hline & Jun. & 19,75 & 19,73 \\
\hline & Jul. & 19,75 & 19,75 \\
\hline & Ago. & 19,75 & 19,74 \\
\hline & Set. & 19,50 & 19,48 \\
\hline & Out. & 19,00 & 18,98 \\
\hline & Nov. & 18,50 & 18,49 \\
\hline & Dez. & 18,00 & 18,00 \\
\hline \multirow{12}{*}{2006} & Jan. & 17,25 & 17,26 \\
\hline & Fev. & 17,25 & 17,26 \\
\hline & Mar. & 16,50 & 16,50 \\
\hline & Abr. & 15,75 & 15,72 \\
\hline & Maio & 15,75 & 15,72 \\
\hline & Jun. & 15,25 & 15,18 \\
\hline & Jul. & 14,75 & 14,67 \\
\hline & Ago. & 14,75 & 14,67 \\
\hline & Set. & 14,25 & 13,19 \\
\hline & Out. & 13,75 & 13,68 \\
\hline & Nov. & 13,25 & 13,18 \\
\hline & Dez. & 13,25 & 13,19 \\
\hline \multirow{12}{*}{2007} & Jan. & 13,00 & 12,93 \\
\hline & Fev. & 13,00 & 12,93 \\
\hline & Mar. & 12,75 & 12,68 \\
\hline & Abr. & 12,50 & 12,43 \\
\hline & Maio & 12,50 & 12,43 \\
\hline & Jun. & 12,00 & 11,93 \\
\hline & Jul. & 11,50 & 11,43 \\
\hline & Ago. & 11,50 & 11,43 \\
\hline & Set. & 11,25 & 11,18 \\
\hline & Out. & 11,25 & 11,18 \\
\hline & Nov. & 11,25 & 11,18 \\
\hline & Dez. & 11,25 & 11,18 \\
\hline \multirow{12}{*}{2008} & Jan. & 11,25 & 11,18 \\
\hline & Fev. & 11,25 & 11,18 \\
\hline & Mar. & 11,25 & 11,18 \\
\hline & Abr. & 11,75 & 11,18 \\
\hline & Maio & 11,75 & 11,63 \\
\hline & Jun. & 12,25 & 12,17 \\
\hline & Jul. & 13,00 & 12,17 \\
\hline & Ago. & 13,00 & 12,92 \\
\hline & Set. & 13,75 & 13,66 \\
\hline & Out. & 13,75 & 13,66 \\
\hline & Nov. & 13,75 & 13,65 \\
\hline & Dez. & 13,75 & 13,66 \\
\hline \multirow{9}{*}{2009} & Jan. & 13,75 & 13,66 \\
\hline & Fev. & 12,75 & 12,66 \\
\hline & Mar. & 11,25 & 11,16 \\
\hline & Abr. & 11,25 & 11,16 \\
\hline & Mai. & 10,25 & 10,16 \\
\hline & Jun. & 9,25 & 9,16 \\
\hline & Jul. & 9,25 & 9,16 \\
\hline & Ago. & 8,75 & 8,65 \\
\hline & Set. & 8,75 & \\
\hline
\end{tabular}

Reservas Internacionais

\begin{tabular}{|c|c|c|c|}
\hline Períc & odo & US\$ milhões & Variação (\%) \\
\hline & Jan. & 54.022 & 2,05 \\
\hline & Fev. & 59.017 & 9,25 \\
\hline & Mar. & 61.960 & 4,99 \\
\hline & Abr. & 61.591 & $-0,60$ \\
\hline & Maio & 60.709 & $-1,43$ \\
\hline 2005 & Jun. & 59.885 & $-1,36$ \\
\hline 2005 & Jul. & 54.688 & $-8,68$ \\
\hline & Ago. & 55.076 & 0,71 \\
\hline & Set. & 57.008 & 3,51 \\
\hline & Out. & 60.245 & 5,68 \\
\hline & Nov. & 64.277 & 6,69 \\
\hline & Dez. & 53.799 & $-16,30$ \\
\hline & Jan. & 56.924 & 5,81 \\
\hline & Fev. & 57.415 & 0,86 \\
\hline & Mar. & 59.824 & 4,20 \\
\hline & Abr. & 56.552 & $-5,47$ \\
\hline & Maio & 63.381 & 12,08 \\
\hline 2006 & Jun. & 62.670 & $-1,12$ \\
\hline 2000 & Jul. & 66.819 & 6,62 \\
\hline & Ago. & 71.478 & 6,97 \\
\hline & Set. & 73.393 & 2,68 \\
\hline & Out. & 78.171 & 6,51 \\
\hline & Nov. & 83.114 & 6,32 \\
\hline & Dez. & 85.670 & 3,08 \\
\hline & Jan. & 91.086 & 6,32 \\
\hline & Fev. & 100.360 & 10,18 \\
\hline & Mar. & 109.517 & 9,12 \\
\hline & Abr. & 121.830 & 11,24 \\
\hline & Maio & 136.419 & 11,97 \\
\hline 2007. & Jun. & 145.501 & 6,66 \\
\hline & Jul. & 155.910 & 7,15 \\
\hline & Ago. & 161.097 & 3,33 \\
\hline & Set. & 162.962 & 1,16 \\
\hline & Out. & 167.867 & 3,01 \\
\hline & Nov. & 177.066 & 5,48 \\
\hline & Dez. & 180.334 & 1,85 \\
\hline & Jan. & 187.507 & 3,98 \\
\hline & Fev. & 192.902 & 2,88 \\
\hline & Mar. & 195.232 & 1,21 \\
\hline & Abr. & 195.767 & 0,27 \\
\hline & Maio & 197.906 & 1,09 \\
\hline 2008 & Jun. & 200.827 & 1,48 \\
\hline & Jul. & 203.562 & 1,36 \\
\hline & Ago. & 205.116 & 0,76 \\
\hline & Set. & 206.494 & 0,67 \\
\hline & Out. & 197.229 & $-4,49$ \\
\hline & Nov. & 194.668 & $-1,30$ \\
\hline & Dez. & 193.783 & $-0,45$ \\
\hline & Jan. & 188.101 & $-2,93$ \\
\hline & Fev. & 186.880 & $-0,65$ \\
\hline & Mar. & 188.251 & 0,73 \\
\hline & Abr. & 190.545 & 1,22 \\
\hline 2009 & Mai. & 195.264 & 2,48 \\
\hline & Jun. & 201.467 & 3,18 \\
\hline & Jul. & 207.363 & 2,93 \\
\hline & Ago. & 215.744 & 4,04 \\
\hline & Set. & 220.931 & 2,40 \\
\hline
\end{tabular}


Setor Externo

\begin{tabular}{|c|c|c|c|c|c|c|}
\hline \multirow{2}{*}{\multicolumn{2}{|c|}{ Período }} & \multicolumn{3}{|c|}{ Balança Comercial } & \multicolumn{2}{|c|}{ Transações Correntes } \\
\hline & & \multirow{2}{*}{$\begin{array}{c}\begin{array}{c}\text { Exportações } \\
\text { (FOB) }^{\mathbf{1}}\end{array} \\
10.963\end{array}$} & \multirow{2}{*}{$\begin{array}{l}\text { Importações } \\
\text { (FOB) }^{\mathbf{1}} \\
8.470\end{array}$} & \multirow{2}{*}{$\begin{array}{r}\text { Saldo }^{1} \\
2.493\end{array}$} & \multirow{2}{*}{$\begin{array}{r}\begin{array}{l}\text { Saldo Transações } \\
\text { Correntes }^{1}\end{array} \\
-378\end{array}$} & \multirow{2}{*}{$\begin{array}{c}\begin{array}{c}\text { Percentual do } \\
\text { PIB em } 12 \text { meses }\end{array} \\
1,25\end{array}$} \\
\hline \multirow{13}{*}{2007} & Jan. & & & & & \\
\hline & Fev. & 10.104 & 7.226 & 2.878 & 376 & 1,20 \\
\hline & Mar. & 12.889 & 9.532 & 3.357 & 233 & 1,09 \\
\hline & Abr. & 12.449 & 8.246 & 4.203 & 1.802 & 1,22 \\
\hline & Maio & 13.648 & 9.780 & 3.868 & -159 & 1,15 \\
\hline & Jun. & 13.118 & 9.303 & 3.815 & 539 & 1,12 \\
\hline & Jul. & 14.120 & 10.773 & 3.347 & -719 & 0,79 \\
\hline & Ago. & 15.100 & 11.566 & 3.534 & 1.350 & 0,71 \\
\hline & Set. & 14.166 & 10.695 & 3.471 & 572 & 0,56 \\
\hline & Out. & 15.769 & 12.330 & 3.439 & -116 & 0,42 \\
\hline & Nov. & 14.052 & 12.025 & 2.027 & -1.318 & 0,20 \\
\hline & Dez. & 14.231 & 10.595 & 3.636 & -469 & 0,13 \\
\hline & Total & 160.609 & 120.540 & 40.068 & 1.712 & - \\
\hline \multirow{13}{*}{2008} & Jan. & 13.277 & 12.354 & 923 & -4.045 & $-0,15$ \\
\hline & Fev. & 12.800 & 11.950 & 849 & -1.913 & $-0,31$ \\
\hline & Mar. & 12.613 & 11.618 & 994 & -4.340 & $-0,64$ \\
\hline & Abr. & 14.058 & 12.321 & 1.738 & -3.176 & $-0,98$ \\
\hline & Maio & 19.303 & 15.233 & 4.070 & -881 & $-1,01$ \\
\hline & Jun. & 18.593 & 15.876 & 2.718 & -2.797 & $-1,22$ \\
\hline & Jul. & 20.451 & 17.134 & 3.318 & -2.221 & $-1,30$ \\
\hline & Ago. & 19.747 & 17.472 & 2.275 & -1.122 & $-1,45$ \\
\hline & Set. & 20.017 & 17.263 & 2.754 & -2.769 & $-1,64$ \\
\hline & Out. & 18.512 & 17.305 & 1.207 & -1.507 & $-1,71$ \\
\hline & Nov. & 14.753 & 13.140 & 1.613 & -976 & $-1,65$ \\
\hline & Dez. & 13.817 & 11.517 & 3.636 & -2.922 & $-1,78$ \\
\hline & Total & 197.943 & 173.184 & 26.094 & -28.670 & \\
\hline \multirow{8}{*}{2009} & Jan. & 9.788 & 10.306 & -518 & -2.764 & $-1,76$ \\
\hline & Fev. & 9.586 & 7.821 & 1.766 & -611 & $-1,72$ \\
\hline & Mar. & 11.809 & 10.038 & 1.771 & -1.645 & $-1,58$ \\
\hline & Abr. & 12.322 & 8.610 & 3.712 & 146 & $-1,40$ \\
\hline & Maio & 11.985 & 9.334 & 2.651 & -1.738 & $-1,50$ \\
\hline & Jun. & 14.468 & 9.843 & 4.625 & -535 & $-1,37$ \\
\hline & Jul. & 14.142 & 11.215 & 2.927 & -1.665 & $-1,35$ \\
\hline & Ago. & 13.826 & 10.766 & 3.059 & -821 & $-1,34$ \\
\hline
\end{tabular}

Fonte: Banco Central do Brasil, SECEX/ MDIC.

Nota: (1) em US\$ milhões. 
Taxa de Câmbio

\begin{tabular}{|c|c|c|c|}
\hline \multirow{2}{*}{\multicolumn{2}{|c|}{ Período }} & \multicolumn{2}{|c|}{ Taxa de câmbio real efetiva } \\
\hline & & IPA-OG & INPC \\
\hline \multirow{12}{*}{2007} & Jan. & 91,86 & 90,49 \\
\hline & Fev. & 90,76 & 89,21 \\
\hline & Mar. & 91,72 & 89,85 \\
\hline & Abr. & 90,80 & 88,74 \\
\hline & Maio & 89,46 & 87,17 \\
\hline & Jun. & 87,55 & 85,12 \\
\hline & Jul. & 86,32 & 84,02 \\
\hline & Ago. & 88,09 & 86,90 \\
\hline & Set. & 85,18 & 85,20 \\
\hline & Out. & 81,62 & 82,22 \\
\hline & Nov. & 81,47 & 82,90 \\
\hline & Dez. & 81,06 & 83,25 \\
\hline \multirow{12}{*}{2008} & Jan. & 81,32 & 83,83 \\
\hline & Fev. & 80,18 & 82,69 \\
\hline & Mar. & 81,98 & 84,79 \\
\hline & Abr. & 81,97 & 85,34 \\
\hline & Maio & 80,26 & 84,60 \\
\hline & Jun. & 78,28 & 83,65 \\
\hline & Jul. & 78,08 & 84,01 \\
\hline & Ago. & 78,27 & 83,37 \\
\hline & Set. & 85,78 & 91,64 \\
\hline & Out. & 97,58 & 105,13 \\
\hline & Nov. & 98,71 & 105,76 \\
\hline & Dez. & 105,61 & 111,84 \\
\hline \multirow{8}{*}{2009} & Jan. & 101,04 & 105,98 \\
\hline & Fev. & 99,66 & 103,88 \\
\hline & Mar. & 97,05 & 99,49 \\
\hline & Abr. & 93,68 & 95,41 \\
\hline & Maio & 92,20 & 93,26 \\
\hline & Jun. & 91,26 & 91,33 \\
\hline & Jul. & 92,79 & 91,57 \\
\hline & Ago. & 92,36 & 91,14 \\
\hline
\end{tabular}

Fonte: IPEA

Nota: Índices ponderados, base ano 2005 $=100$. 
Agregados Monetários

\begin{tabular}{|c|c|c|c|c|c|}
\hline \multicolumn{2}{|c|}{ Período } & $\begin{array}{c}\text { Base } \\
\text { monetária* }\end{array}$ & $\mathbf{M 1}^{1}$ & $\mathbf{M} 2^{2}$ & $\mathbf{M}^{3}$ \\
\hline \multirow{12}{*}{2007} & Jan & 4,48 & 6,35 & 26,37 & 56,82 \\
\hline & Fev. & 4,26 & 6,23 & 26,24 & 57,04 \\
\hline & Mar. & 4,32 & 6,27 & 26,21 & 56,95 \\
\hline & Abr. & 4,57 & 6,26 & 26,27 & 57,62 \\
\hline & Maio & 4,30 & 6,27 & 26,34 & 57,89 \\
\hline & Jun. & 4,55 & 6,46 & 26,65 & 58,20 \\
\hline & Jul. & 4,50 & 6,49 & 26,54 & 58,30 \\
\hline & Ago. & 4,38 & 6,51 & 26,73 & 57,80 \\
\hline & Set. & 4,56 & 6,62 & 26,95 & 58,50 \\
\hline & Out. & 4,60 & 6,66 & 27,03 & 58,73 \\
\hline & Nov. & 4,83 & 6,94 & 27,16 & 58,57 \\
\hline & Dez. & 5,36 & 8,46 & 28,55 & 59,11 \\
\hline \multirow{12}{*}{2008} & Jan. & 4,73 & 6,90 & 27,40 & 58,61 \\
\hline & Fev. & 4,55 & 6,62 & 27,29 & 58,78 \\
\hline & Mar. & 4,60 & 6,57 & 27,80 & 58,92 \\
\hline & Abr. & 4,38 & 6,57 & 28,56 & 59,31 \\
\hline & Maio & 4,60 & 6,33 & 29,03 & 59,20 \\
\hline & Jun. & 4,51 & 6,33 & 29,38 & 58,71 \\
\hline & Jul. & 4,36 & 6,28 & 30,62 & 59,72 \\
\hline & Ago. & 4,47 & 6,32 & 32,14 & 60,96 \\
\hline & Set. & 4,60 & 6,54 & 33,17 & 61,18 \\
\hline & Out. & 4,42 & 6,32 & 33,78 & 60,96 \\
\hline & Nov. & 4,42 & 6,62 & 34,58 & 62,31 \\
\hline & Dez. & 4,97 & 7,52 & 36,12 & 64,14 \\
\hline \multirow{8}{*}{2009} & Jan. & 4,65 & 6,62 & 35,62 & 64,38 \\
\hline & Fev. & 4,64 & 6,62 & 36,11 & 65,40 \\
\hline & Mar. & 4,63 & 6,60 & 36,30 & 66,35 \\
\hline & Abr. & 4,97 & 6,74 & 36,51 & 67,26 \\
\hline & Mai. & 4,57 & 6,69 & 36,86 & 68,23 \\
\hline & Jun. & 4,79 & 6,99 & 37,67 & 69,12 \\
\hline & Jul. & 4,65 & 6,87 & 37,74 & 69,97 \\
\hline & Ago. & 4,67 & 6,90 & 37,63 & 70,63 \\
\hline
\end{tabular}

Fonte: Banco Central do Brasil.

Nota: $(*)$ base monetária em \% do PIB.
(1) M1 - fim de período - \% PIB.
(2) M2 - fim de período - conceito novo - \% PIB.
(3) M3 - fim de período - conceito novo - \% PIB. 